\title{
Premedication with Oral Alprazolam and Melatonin Combination: A Comparison with Either Alone-A Randomized Controlled Factorial Trial
}

\author{
Krishna Pokharel, ${ }^{1}$ Mukesh Tripathi, ${ }^{1,2}$ Pramod Kumar Gupta, ${ }^{1,3}$ Balkrishna Bhattarai, ${ }^{1}$ \\ Sindhu Khatiwada, ${ }^{1}$ and Asish Subedi ${ }^{1}$ \\ ${ }^{1}$ Department of Anesthesiology and Critical Care, B. P. Koirala Institute of Health Sciences, Dharan 56700, Nepal \\ ${ }^{2}$ Department of Anesthesiology, Sanjay Gandhi Post Graduate Institute of Medical Sciences, Lucknow 226014, India \\ ${ }^{3}$ Department of Anesthesiology, Banaras Hindhu University, Varanasi 221005, India
}

Correspondence should be addressed to Krishna Pokharel; drkrishnapokharel@gmail.com

Received 10 April 2013; Accepted 7 October 2013; Published 12 January 2014

Academic Editor: Christina Pabelick

Copyright (c) 2014 Krishna Pokharel et al. This is an open access article distributed under the Creative Commons Attribution License, which permits unrestricted use, distribution, and reproduction in any medium, provided the original work is properly cited.

\begin{abstract}
We assessed if the addition of melatonin to alprazolam has superior premedication effects compared to either drug alone. A prospective, double blind placebo controlled trial randomly assigned 80 adult patients (ASA 1\&2) with a Visual Analogue Score (VAS) for anxiety $\geq 3$ to receive a tablet containing a combination of alprazolam $0.5 \mathrm{mg}$ and melatonin $3 \mathrm{mg}$, alprazolam $0.5 \mathrm{mg}$, melatonin $3 \mathrm{mg}$, or placebo orally $90 \mathrm{~min}$ before a standard anesthetic. Primary end points were change in anxiety and sedation score at 15,30, and $60 \mathrm{~min}$ after premedication, and number of patients with loss of memory for the five pictures shown at various time points when assessed after $24 \mathrm{~h}$. One-way ANOVA, Friedman repeated measures analysis of variance, Kruskal Wallis and chi square tests were used as relevant. Combination drug produced the maximum reduction in anxiety VAS (3 (1.0-4.3)) from baseline at $60 \mathrm{~min}(P<0.05)$. Sedation scores at various time points and number of patients not recognizing the picture shown at $60 \mathrm{~min}$ after premedication were comparable between combination drug and alprazolam alone. Addition of melatonin to alprazolam had superior anxiolysis compared with either drugs alone or placebo. Adding melatonin neither worsened sedation score nor the amnesic effect of alprazolam alone. This study was registered, approved, and released from ClinicalTrials.gov. Identifier number: NCT01486615.
\end{abstract}

\section{Introduction}

Benzodiazepines are amongst the most popular preoperative medication to produce anxiolysis, amnesia, and sedation for the patients coming for surgery [1]. Benzodiazepines are reported to be paradoxically associated with the increased episodes of arousal during sleep, restlessness, and hangover effects [2]. Alprazolam, a benzodiazepine class of antipsychotic drugs, is more anxioselective than the other premedicants of this group like midazolam, lorazepam, or diazepam [3]. It has also been reported to show arousal episodes [2].

Melatonin (N-acetyl-5-methoxytryptamine), an endogenous pineal hormone when given orally as premedicant, also results in preoperative anxiolysis and sedation $[4,5]$.
It neither impairs cognitive and psychomotor skills nor the quality of recovery $[4,5]$. Its anxiolytic, sedative, hypnotic, analgesic, anti-inflammatory, antioxidative, and chronobiotic properties distinguish it as an attractive alternative premedicant [6].

Benzodiazepines are associated with the suppression of endogenous melatonin levels to probably show the increased episodes of arousal during sleep, restlessness, and hang over effects [2]. We hypothesize that the arousal episodes produced by alprazolam can be reduced by combining it with exogenous melatonin, hence might promote sound sleep to improve upon preoperative stress. To our knowledge, combination of melatonin and alprazolam as premedicant has not been evaluated. Hence, we designed this prospective, 
randomized, double blind placebo controlled factorial trial to assess whether addition of melatonin to alprazolam has any advantage over alprazolam or melatonin alone in premedication.

\section{Methods}

After getting approval from the institutional research ethics committee and written informed consent from each patient, we studied eighty ASA 1 and 2 patients, aged 18 to $65 \mathrm{yr}$ having anxiety VAS score of three or more, planned for receiving general anesthesia for laparoscopic cholecystectomy. Patients taking analgesics, sedatives, antiepileptics, or antidepressants, suffering from obesity (BMI $\geq 28$ ) or neuropsychiatric disease, having history of allergy to the study drugs were excluded.

With the help of computer generated random numbers that were concealed until after the consent was obtained, patients were assigned to one of the four groups of twenty each. Group one patients were administered a tablet containing the combination of oral alprazolam $(0.5 \mathrm{mg})$ and melatonin ( $3 \mathrm{mg}$ ). Group two patients received alprazolam $(0.5 \mathrm{mg})$. Group three patients received melatonin $(3 \mathrm{mg})$. Group four patients were administered a similar looking placebo tablet. All patients received only one tablet with sips of plain water, approximately $90 \mathrm{~min}$ before surgery.

One day prior to surgery on the preanesthetic visit, all the patients were explained about the nature of the study and the various scales to be used. A $10 \mathrm{~cm}$ linear Visual Analogue Scale (VAS) [7] was used to assess their anxiety levels. The extremes of the VAS anxiety scale were marked as "no anxiety" at the 0 end and "anxiety as bad as ever can be" at the $10 \mathrm{~cm}$ end. Sedation was assessed on a five-point scale $(0=$ alert, $1=$ arouses to voice, $2=$ arouses with gentle tactile stimulation, 3 = arouses with vigorous tactile stimulation, and 4 = lack of responsiveness) [8] and orientation, with a threepoint scale $(0=$ none, $1=$ orientation in either time or place, and 2 = orientation in both) [4]. To test for the memory, recall of five different simple pictures and two events were assessed. Pictures to be used were sequentially numbered on the back and their names printed on the front.

Approximately 90 min prior to surgery, each patient was taken to a quiet room. Noninvasive blood pressure, heart rate, respiratory rate, and $\mathrm{SpO}_{2}$ were monitored. Then picture one (cup on a plate) and two (fruits) were shown $10 \mathrm{~min}$ before and just prior to the drug administration, respectively. Patients were asked to take the study medication orally with $15 \mathrm{~mL}$ of plain water according to the group assignment by an investigator not involved in the patient management or data collection thereafter. Anxiety, sedation, and orientation scores were assessed just prior to and at $15 \mathrm{~min}, 30 \mathrm{~min}$, and $60 \mathrm{~min}$ after the drug administration. At these time points pictures three (birds), four (hare), and five (car) were also shown, respectively.

In the operating room, intravenous access was secured and meperidine $1 \mathrm{mg} / \mathrm{kg}$ administered intravenously. Then intravenous lidocaine $20 \mathrm{mg}$ bolus was administered followed by propofol via infusion pump at $100 \mathrm{~mL} / \mathrm{h}$ till loss of response to verbal command and loss of eyelash reflex were noticed. Vecuronium $0.1 \mathrm{mg} / \mathrm{kg}$ and isoflurane in oxygen were administered to maintain the adequate depth of anesthesia. After intubation, ventilation was adjusted to maintain normocapnia. Incremental doses of the injection meperidine $(0.1 \mathrm{mg} / \mathrm{kg})$ and vecuronium $(0.02 \mathrm{mg} / \mathrm{kg})$ were given as required. Intravenous diclofenac sodium $75 \mathrm{mg}$ was administered slowly $15 \mathrm{~min}$ prior to completion of surgery for postoperative analgesia. After completion of surgery, intravenous neostigmine $(50 \mu \mathrm{gm} / \mathrm{kg})$, and glycopyrrolate $(10 \mu \mathrm{gm} / \mathrm{kg})$ were given to reverse the residual muscle paralysis. Anesthesia time (induction to emergence) was noted.

In the recovery room, patients received the standard postoperative care, including oxygen administration via face mask $(6 \mathrm{~L} / \mathrm{min})$ and monitoring of heart rate, respiratory rate, noninvasive blood pressure and $\mathrm{SpO}_{2}$. We observed for any episodes of nausea, vomiting, dizziness, headache, and restlessness in the next $24 \mathrm{~h}$. Intravenous ondansetron ( $4 \mathrm{mg}$ ) was given slowly to treat postoperative nausea and vomiting.

After $24 \mathrm{~h}$ following surgery, the patients were asked if they recalled the two events, viz. being transported to the operating room and intravenous cannula being inserted. They were also asked to have a free recall of the five pictures they were shown. Then, the first five pictures that were shown were mixed with five new pictures (of a horse, shoe, bicycle, elephant, and tiger) and they were asked to recognize the pictures which were shown before surgery. They were also asked whether they would like to receive the same premedication drug in the future if required.

The primary end points were change in anxiety, sedation, and orientation scores at various time points after premedication and the number of patients with loss of memory for the five pictures $24 \mathrm{~h}$ later. Secondary outcome was the number of patients who desired to receive the same premedication drug in the future if required.

2.1. Statistical Analysis. Before the study began, a sample size of 16 patients in each group was determined by a power analysis $(\alpha, 0.05 ; \beta, 0.10)$ on the basis of the assumption that there will be $50 \%$ reduction in anxiety VAS from baseline in the experimental groups and $4 \%$ in the placebo group. To compensate for drop out cases and shifting from normality in data distribution, 20 cases were studied in each group.

Data were tested for normal distribution using Kolmogorov-Smirnov test. To identify differences between groups, one-way analysis of variance (ANOVA) was used for normally distributed continuing data and chi square tests for categorical data. As the anxiety and sedation scores were not normally distributed; they were thus analyzed with nonparametric statistical methods. Friedman repeated measures analysis of variance followed by Wilcoxon tests with Bonferroni correction were used for within-group comparison of values between different time points. Kruskal Wallis tests with post hoc multiple comparisons by Mann Whitney $U$ test were used for the comparison of values between the groups at each time points. Parametric data were expressed as the mean $\pm \mathrm{SD}$ and nonparametric data 
as median (interquartile range). A $P$ value $<0.05$ was considered significant.

\section{Results}

One hundred and ten patients were assessed for eligibility, 98 patients had anxiety VAS $\geq 3$. Among the 80 enrolled patients who were observed till two hours after premedication, the surgery was postponed in five patients because of limited operating room time. These patients were discharged on the same day and were not available for the assessment at $24 \mathrm{~h}$ after premedication (Figure 1). Patients in the four groups were comparable in demographic characteristics and perioperative parameters (Table 1).

3.1. Report on Anxiety. VAS anxiety scores were significantly $(P<0.001)$ reduced relative to baseline at various time points in all the groups $\left\{\chi^{2}(\mathrm{df})=43.6(3)\right.$ for melatonin and alprazolam, $\chi^{2}(\mathrm{df})=39.5(3)$ for alprazolam, $\chi^{2}(\mathrm{df})=31.5(3)$ for melatonin $\}$ except in placebo $\left(\chi^{2}(\mathrm{df})=6.8, P>0.05\right)$ (Figure 2). Wilcoxon tests with Bonferroni correction (effects reported at a 0.0167 level of significance) revealed that these within group differences were significant only at $30 \mathrm{~min}$ and 60 min relative to baseline in all the three groups.

When compared in between the groups, the reduction in anxiety VAS from baseline were significantly different only at 60 min after premedication $\{H(3)=11.8, P=0.008\}$. Mann Whitney tests with Bonferroni correction (effects reported at a 0.01 level of significance) were used to follow up this finding. The reduction in anxiety VAS \{median (interquartile range) was significantly different only between the groups receiving the combination drugs $\{3(1.0-4.3) \mathrm{cm}\}$ and placebo $\{0(0-1.7)$ $\mathrm{cm}\}(U=86.5, z=-3.18, P=0.008)$ (Figure 2).

3.2. Report on Sedation. Sedation scores were significantly increased relative to baseline at various time points in all the groups $\left\{\chi^{2}(\mathrm{df})=34.9(3), P<0.001\right.$ for melatonin and alprazolam combination, $\chi^{2}(\mathrm{df})=31.9(3), P<0.001$ for alprazolam, $\chi^{2}(\mathrm{df})=18.4(3), P<0.001$ for melatonin $\}$ including placebo $\left(\chi^{2}(\mathrm{df})=12.6(3), P=0.006\right)$ (Figure 2$)$. To follow up this finding, Wilcoxon tests with Bonferroni correction were applied; so all effects are reported at a 0.0167 level of significance. While the increment in sedation score relative to baseline was significant at only $60 \mathrm{~min}$ in placebo, the differences were significant at both 30 and 60 min after premedication in rest of the three groups.

When the sedation scores \{median (interquartile range)\} were compared in between groups, the difference was significant at only 60 min after premedication $\{H(3)=18.5, P<$ $0.001\}$. Mann Whitney tests with Bonferroni correction (effects reported at a 0.00714 level of significance) were used to follow up this finding. The difference was significant only between the groups receiving combination drugs $\{1$ (1.0$1.75)\}$ and placebo $\{0(0-1)\}(U=86.5, z=-3.18, P=0.008)$, and between the groups receiving the combination drugs $\{1$ $(1.0-1.75)\}$ and melatonin $\{0.5(0-1)\}(U=85, z=-3.33$, $P=0.001)$. Details of the sedation scores are given in Table 2 .
3.3. Report on Orientation. All the patients had orientation score of 2 at $15 \mathrm{~min}, 30 \mathrm{~min}$ and $60 \mathrm{~min}$ after premedication.

3.4. Report on Amnesia. More number of patents in groups receiving the combination drugs and alprazolam (9 each) did not recognize the picture shown at $60 \mathrm{~min}$ after premedication compared to groups receiving melatonin and placebo (2 each) $(P<0.05)$. Amnesia for two events was notable in maximum number of patients in the group receiving the combination of alprazolam and melatonin. However, the difference was statistically significant only between the groups receiving the combination drugs (5 (26\%)) and placebo (0) for only one event (shifting to the operating room) (Table 3 ).

3.5. Patient's Perception. Except for the one patient who was not sure, all the patients who received the combination of alprazolam and melatonin stated they would prefer to have the same premedication in the future. Two (11\%) in alprazolam group, five $(25 \%)$ in melatonin group and six (33\%) patients in placebo group expressed a change to other premedicant in future.

3.6. Safety Profile. There was no statistical difference between the groups in the number of people reporting occurrence of nausea, vomiting, dizziness, headache, or restlessness (Table 1).

\section{Discussion}

We have found that the melatonin alprazolam combination reduced anxiety level to a greater extent than the either drug alone. All three premedicants put the patients to sleep earlier than placebo. The combined premedication did not worsen sedation than the alprazolam. Amnesia was notable in patients receiving melatonin alprazolam combination and alprazolam alone. Almost all the patients receiving the melatonin alprazolam combination preferred to have the same premedicant in the future. All the three premedication drugs were safe in terms of the side effects observed till $24 \mathrm{~h}$ after surgery.

Benzodiazepines are the most common premedicant before surgery to alleviate preoperative anxiety [1]. Benzodiazepines enhance the effect of the neurotransmitter gamma amino butyric acid (GABA), to show sedation, anxiolysis, amnesia, muscle relaxation, and anticonvulsant effects. In a Belgian study, oral alprazolam $(0.5 \mathrm{mg})$ produced significant levels of sedation (sedation VAS $23 \pm 20 \mathrm{~mm}$ ) compared to placebo (sedation VAS $7 \pm 20 \mathrm{~mm}$ ) at 60 to $90 \mathrm{~min}$ after premedication in patients planned for day care surgery [8]. In our patients alprazolam produced more sedation scores than placebo at $60 \mathrm{~min}$ after premedication, but the difference was not statistically significant. However, our patients who received alprazolam got sedated half an hour earlier than placebo.

Melatonin is a naturally occurring pineal hormone in the human body which regulates the circadian rhythm [9]. Its levels are high during night time sleep [9]. Oral administration of 1-5 mg of melatonin results in plasma levels of 10-100 


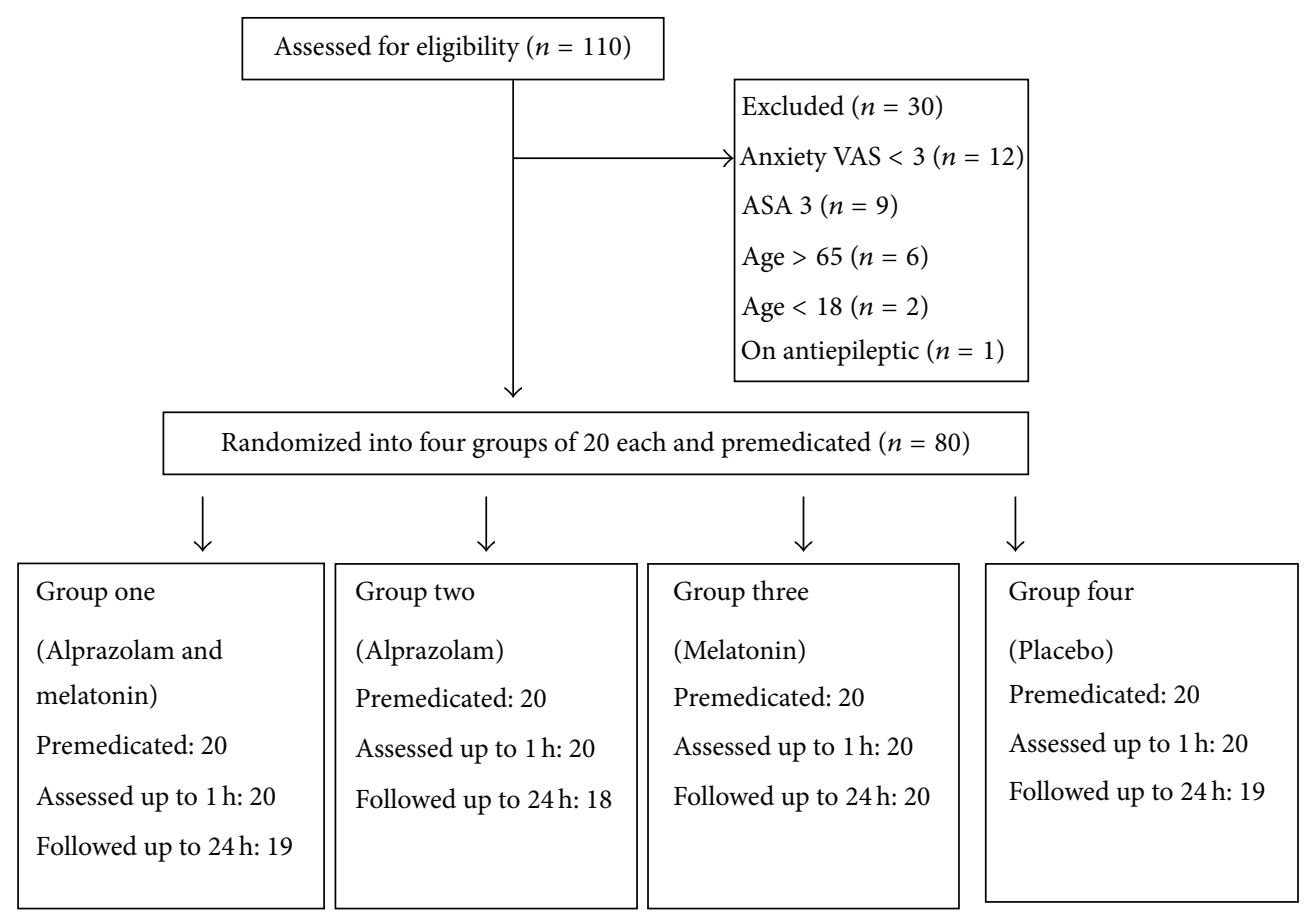

FIGURE 1: A flow diagram showing inclusion, exclusion, group allocation, intervention and follow up.

TABLE 1: Patient data and perioperative variables. Values are expressed as number (\%), mean \pm SD or median (interquartile range) as applicable. No significant differences.

\begin{tabular}{|c|c|c|c|c|}
\hline & Melatonin and Alprazolam & Alprazolam & Melatonin & Placebo \\
\hline \multicolumn{5}{|l|}{ Patients data } \\
\hline Number of patients $(n)$ & 20 & 20 & 20 & 20 \\
\hline Gender (male/female) & $6 / 14$ & $4 / 16$ & $4 / 16$ & $5 / 15$ \\
\hline Age (yr) & $38 \pm 14$ & $37 \pm 10$ & $34 \pm 11$ & $36 \pm 13$ \\
\hline Weight (kg) & $52 \pm 7$ & $52 \pm 7$ & $57 \pm 11$ & $57 \pm 12$ \\
\hline History of previous surgery $(n)$ & $11(55)$ & $8(40)$ & $8(40)$ & $9(45)$ \\
\hline VAS baseline $(\mathrm{cm})$ & $5(3.6-6)$ & $5(4.2-7)$ & $5(4-6)$ & $5(4-6)$ \\
\hline \multicolumn{5}{|l|}{ Perioperative variables } \\
\hline Number of patients $(n)$ & 19 & 18 & 20 & 18 \\
\hline \multicolumn{5}{|l|}{ Propofol (mg) consumed until } \\
\hline Loss of verbal command & $66 \pm 21$ & $59 \pm 21$ & $79.2 \pm 4$ & $75.8 \pm 25$ \\
\hline Loss of eyelash reflex & $73 \pm 22$ & $62 \pm 22$ & $79 \pm 35$ & $80.8 \pm 29$ \\
\hline Anesthesia time (min) & $77 \pm 34$ & $73 \pm 21$ & $66 \pm 18$ & $72 \pm 18$ \\
\hline \multicolumn{5}{|l|}{ Patients $(n)$ with } \\
\hline Nausea and vomiting & $8(42)$ & $6(33)$ & $7(35)$ & $9(50)$ \\
\hline Headache & $4(21)$ & $3(17)$ & $4(20)$ & $5(28)$ \\
\hline Dizziness & $3(16)$ & $2(11)$ & $5(25)$ & $4(22)$ \\
\hline Restlessness & $7(37)$ & $9(50)$ & $6(30)$ & $8(44)$ \\
\hline
\end{tabular}

times more than the observed endogenous night time levels [9]. Oral melatonin ( $5 \mathrm{mg}$ ) is reported to cause significant sedation at 60-90 min after premedication [4]. We too found that the melatonin administration was associated with earlier onset of sleep than the placebo.

Interestingly, all our patients got significantly sedated at one hour of the stay in preoperative waiting room from their baseline level of sedation score. It could be corroborated with their stay in isolation at the quiet preoperative waiting room where they were shifted for the study purpose.

We have found that adding melatonin to alprazolam reduced anxiety levels more than either of the two drugs given alone. Although the exact mechanism of the action of melatonin is still not known, there is accumulating evidence that a synergy exists between the melatonergic and GABAergic systems. It has been reported that the melatonin 
TABLE 2: Showing sedation in the four groups at various time points after premedication. Values are expressed as number of patients (\%).

\begin{tabular}{|c|c|c|c|c|}
\hline & $\begin{array}{l}\text { Melatonin and Alprazolam } \\
\qquad(n=20)\end{array}$ & $\begin{array}{l}\text { Alprazolam } \\
(n=20)\end{array}$ & $\begin{array}{l}\text { Melatonin } \\
(n=20)\end{array}$ & $\begin{array}{l}\text { Placebo } \\
(n=20)\end{array}$ \\
\hline \multicolumn{5}{|l|}{ Baseline } \\
\hline Alert & $18(90)$ & $20(100)$ & $17(85)$ & $20(100)$ \\
\hline Arouses to voice & $2(10)$ & $0(0)$ & $3(15)$ & $0(0)$ \\
\hline \multicolumn{5}{|l|}{15 min after premedication } \\
\hline Alert & $13(65)$ & $16(80)$ & $13(65)$ & $18(90)$ \\
\hline Arouses to voice & $4(20)$ & $4(20)$ & $6(30)$ & $2(10)$ \\
\hline Arouses with gentle tactile stimulation & $3(15)$ & $0(0)$ & $1(5)$ & $0(0)$ \\
\hline \multicolumn{5}{|l|}{30 min after premedication } \\
\hline Alert & $7(35)$ & $10(50)$ & $9(45)$ & $15(75)$ \\
\hline Arouses to voice & $8(40)$ & $6(30)$ & $8(40)$ & $4(20)$ \\
\hline Arouses with gentle tactile stimulation & $4(20)$ & $4(20)$ & $3(15)$ & $1(5)$ \\
\hline Arouses with vigorous tactile stimulation & $1(5)$ & $0(0)$ & $0(0)$ & $0(0)$ \\
\hline \multicolumn{5}{|l|}{60 min after premedication } \\
\hline Alert & $3(15)$ & $6(30)$ & $10(50)$ & $12(60)$ \\
\hline Arouses to voice & $8(40)$ & $9(45)$ & $7(35)$ & $8(40)$ \\
\hline Arouses with gentle tactile stimulation & $4(20)$ & $4(20)$ & $3(15)$ & $0(0)$ \\
\hline Arouses with vigorous tactile stimulation & $5(25)$ & $1(5)$ & $0(0)$ & $0(0)$ \\
\hline
\end{tabular}

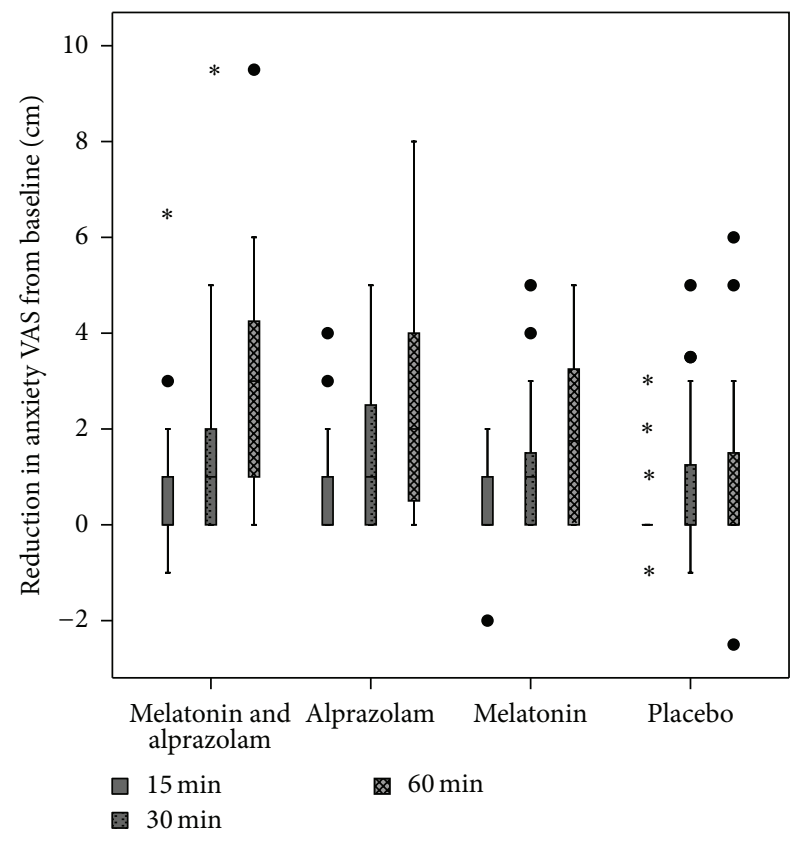

FIGURE 2: Change in anxiety VAS (median (IR)) relative to baseline after premedication. $\bullet=$ outlier, $*=$ extreme value.

administration is associated with significant, dose-dependent increases in GABA concentrations in the central nervous system [10]. We observed that the added dose of melatonin in combination with alprazolam caused similar levels of sedation as seen with alprazolam alone suggesting that the melatonin in doses we used did not worsen sedation levels.
Benzodiazepines are reported to impair psychomotor performance $[5,8]$. The reports of the effect of melatonin on the orientation score with respect to time and place has varied in the literature $[4,5,11]$. Since we only recorded the orientation score to time and place in our patients, it remained preserved in perioperative period of study.

Several studies have reported that melatonin lacks antegrade amnesia $[4,5,11,12]$. The incidence of amnesia in our patients receiving melatonin was low, and comparable to placebo. Alprazolam at doses of $0.5 \mathrm{mg}$ and higher has been reported to impair immediate and delayed recall and recognition [13]. Adding melatonin to alprazolam did not change the amnesic effects in our patients.

Interestingly majority of our patients premedicated with the combination of melatonin with alprazolam, expressed their desire to get similar premedication in future too. Benzodiazepines are associated with episodes of arousal during sleep [2] and later also show hangover effects [4] as they decrease the duration of rapid eye movement and slow wave sleep [14]. In contrast, melatonin is known to improve the quality of sleep [15]. While benzodiazepines are reported to decrease melatonin levels [2], the combined medication probably improved the quality of sleep in preoperative period to improve liking of the patients for the combined premedication than either drug alone or placebo. However, as our study was not designed to address the precise reason for preferring for the combined medication, for example, better anxiolysis or sleep or both, we cannot comment on this further.

All the drugs we used were safe in terms of adverse effects encountered. The minor problems that our patients complained were headache, restlessness, dizziness, nausea, and vomiting and their frequencies were similar in patients 
TABLE 3: Showing the result of assessment of memory for the five pictures shown at various time points related to premedication on the previous day and the two events. Values are expressed as number of patients (\%).

\begin{tabular}{|c|c|c|c|c|c|}
\hline & $\begin{array}{l}\text { Melatonin and Alprazolam } \\
\qquad(n=19)\end{array}$ & $\begin{array}{l}\text { Alprazolam } \\
(n=18)\end{array}$ & $\begin{array}{l}\text { Melatonin } \\
(n=20)\end{array}$ & $\begin{array}{l}\text { Placebo } \\
(n=18)\end{array}$ & $P$ value \\
\hline \multicolumn{6}{|c|}{ Picture 1 (shown 10 min prior to premedication) } \\
\hline Recalled & $15(79)$ & $17((94)$ & $15(75)$ & $14(78)$ & \multirow{2}{*}{0.178} \\
\hline Recognized & $19(100)$ & $18(100)$ & $20(100)$ & $18(100)$ & \\
\hline \multicolumn{6}{|c|}{ Picture 2 (shown just prior to premedication) } \\
\hline Recalled & $15(79)$ & $14(78)$ & $13(65)$ & $15(83)$ & \multirow{2}{*}{0.965} \\
\hline Recognized & $19(100)$ & $18(100)$ & $20(100)$ & $18(100)$ & \\
\hline \multicolumn{6}{|c|}{ Picture 3 (shown 15 min after premedication) } \\
\hline Recalled & $15(79)$ & $17(94)$ & $13(65)$ & $13(72)$ & \multirow{2}{*}{0.051} \\
\hline Recognized & $17(89)$ & $18(100)$ & $20(100)$ & $18(100)$ & \\
\hline \multicolumn{6}{|c|}{ Picture 4 (shown 30 min after premedication) } \\
\hline Recalled & $9(47)$ & $8(44)$ & $10(50)$ & $14(78)$ & \multirow{2}{*}{0.255} \\
\hline Recognized & $16(84)$ & $15(83)$ & $19(95)$ & $18(100)$ & \\
\hline \multicolumn{6}{|c|}{ Picture 5 (shown 60 min after premedication) } \\
\hline Recalled & $4(21)$ & $5(28)$ & $13(65)$ & $14(78)$ & \multirow{2}{*}{0.003} \\
\hline Recognized & $10(53)$ & $9(50)$ & $18(90)$ & $16(89)$ & \\
\hline \multicolumn{6}{|c|}{ Event 1 (transfer to operating room) } \\
\hline Recalled & $14(74)$ & $14(78)$ & $19(95)$ & $18(100)$ & 0.047 \\
\hline \multicolumn{6}{|c|}{ Event 2 (intravenous cannulation) } \\
\hline Recalled & $12(63)$ & $14(78)$ & $18(90)$ & $16(89)$ & 0.135 \\
\hline
\end{tabular}

of all study groups. However, our study was not statistically powered to detect the incidence of adverse events. Both melatonin and alprazolam are reported to be safe $[16,17]$ and serious untoward effects have not been documented in the therapeutic range so far.

The limitations of our study include a small sample size considering the factorial trial of the two premedicant drugs and limited tests of the orientation score and the delayed visual episodic memory in place of the detailed psychomotor and battery of memory tests. Further, we also could not measure the blood levels of the studied drugs because of lack of facility.

\section{Conclusion}

While melatonin alprazolam combination reduced anxiety better than either drug alone, it produced sedation and amnesia to a similar degree as alprazolam alone. More patients desired to receive the melatonin and alprazolam combination as premedicant in the future. Authors recommend the use of combination of alprazolam with melatonin orally as premedicant in surgical patients.

\section{Conflict of Interests}

The authors declare that there is no conflict of interests regarding the publication of this paper.

\section{Acknowledgment}

The study was conducted with the research grant from B. P. Koirala Institute of Health Science (BPKIHS), Dharan, Nepal.

\section{References}

[1] J. R. Moyers and C. M. Vincent, "Preoperative medication," in Clinical Anesthesia, P. G. Barash, B. F. Cullen, and R. K. Stoelting, Eds., pp. 551-563, Lippincott-Raven, Philadelphia, Pa, USA, 4th edition, 1997.

[2] D. Dawson and N. Encel, "Melatonin and sleep in humans," Journal of Pineal Research, vol. 15, no. 1, pp. 1-12, 1993.

[3] M. Ansseau, A. Doumont, and S. Diricq, "Methodology required to show clinical differences between benzodiazepines," Current Medical Research and Opinion, vol. 8, no. 4, pp. 108-114, 1984.

[4] M. Naguib and A. H. Samarkandi, "Premedication with melatonin: a double-blind, placebo-controlled comparison with midazolam," British Journal of Anaesthesia, vol. 82, no. 6, pp. 875-880, 1999.

[5] M. Naguib and A. H. Samarkandi, "The comparative doseresponse effects of melatonin and midazolam for premedication of adult patients: a double-blinded, placebo-controlled study," Anesthesia and Analgesia, vol. 91, no. 2, pp. 473-479, 2000.

[6] F. Yousaf, E. Seet, L. Venkatraghavan, A. Abrishami, and F. Chung, "Efficacy and safety of melatonin as an anxiolytic and analgesic in the perioperative period: a qualitative systematic review of randomized trials," Anesthesiology, vol. 113, no. 4, pp. 968-976, 2010. 
[7] R. C. Aitken, "Measurement of feelings using visual analogue scales," Proceedings of the Royal Society of Medicine, vol. 62, no. 10, pp. 989-993, 1969.

[8] J. L. De Witte, C. Alegret, D. I. Sessler, and G. Cammu, "Preoperative alprazolam reduces anxiety in ambulatory surgery patients: a comparison with oral midazolam," Anesthesia and Analgesia, vol. 95, no. 6, pp. 1601-1606, 2002.

[9] A. Brzezinski, "Melatonin in humans," The New England Journal of Medicine, vol. 336, no. 3, pp. 186-195, 1997.

[10] M. Naguib, V. Gottumukkala, and P. A. Goldstein, "Melatonin and anesthesia: a clinical perspective," Journal of Pineal Research, vol. 42, no. 1, pp. 12-21, 2007.

[11] M. Capuzzo, B. Zanardi, E. Schiffino et al., "Melatonin does not reduce anxiety more than placebo in the elderly undergoing surgery," Anesthesia and Analgesia, vol. 103, no. 1, pp. 121-123, 2006.

[12] D. Ionescu, C. Bãdescu, C. Itie et al., "Melatonin as premedication for laparoscopic cholecystectomy: a double-blind, placebocontrolled study," Southern African Journal of Anaesthesia and Analgesia, vol. 14, no. 4, pp. 8-11, 2008.

[13] J. C. Verster and E. R. Volkerts, "Clinical pharmacology, clinical efficacy, and behavioral toxicity of alprazolam: a review of the literature," CNS Drug Reviews, vol. 10, no. 1, pp. 45-76, 2004.

[14] A. A. Borbely, P. Mattmann, and M. Loepfe, "Effect of benzodiazepine hypnotics on all-night sleep EEG spectra," Human Neurobiology, vol. 4, no. 3, pp. 189-194, 1985.

[15] R. J. Wurtman and I. Zhdanova, "Improvement of sleep quality by melatonin," The Lancet, vol. 346, no. 8988, p. 1491, 1995.

[16] M. L. V. De Seabra, M. Bignotto, L. R. Pinto Jr., and S. Tufik, "Randomized, double-blind clinical trial, controlled with placebo, of the toxicology of chronic melatonin treatment," Journal of Pineal Research, vol. 29, no. 4, pp. 193-200, 2000.

[17] G. W. Dawson, S. G. Jue, and R. N. Brogden, "Alprazolam. A review of its pharmacodynamic properties and efficacy in the treatment of anxiety and depression," Drugs, vol. 27, no. 2, pp. 132-147, 1984. 


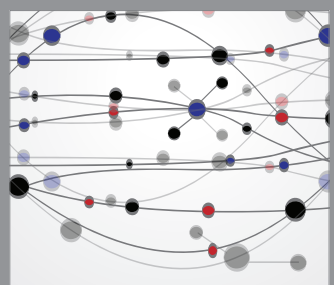

The Scientific World Journal
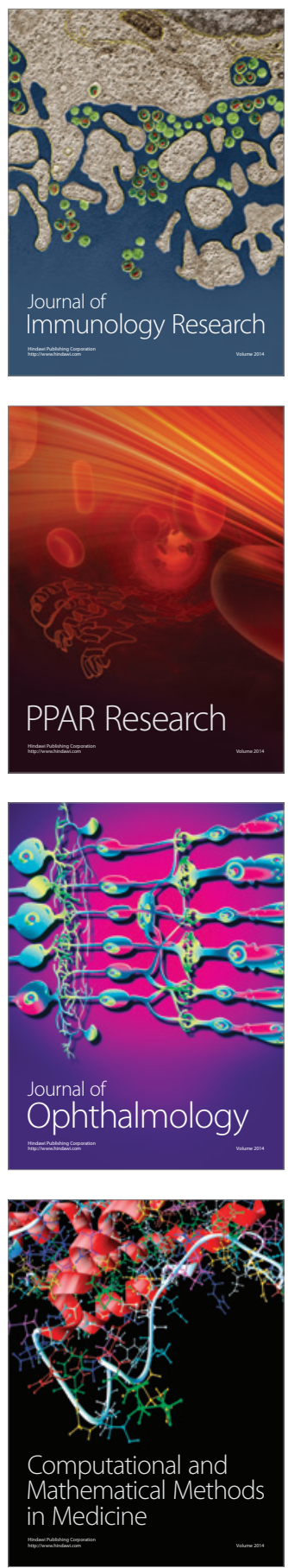

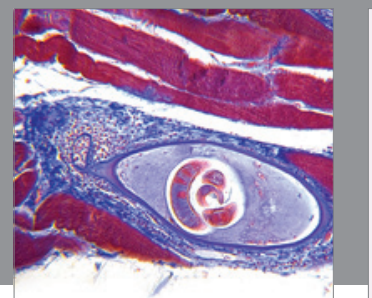

Gastroenterology

Research and Practice
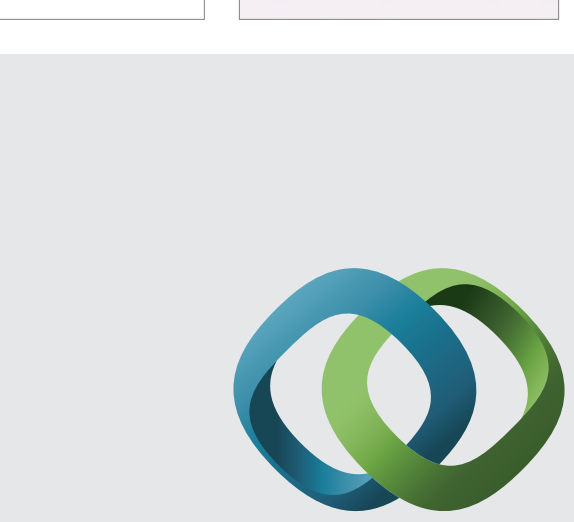

\section{Hindawi}

Submit your manuscripts at

http://www.hindawi.com
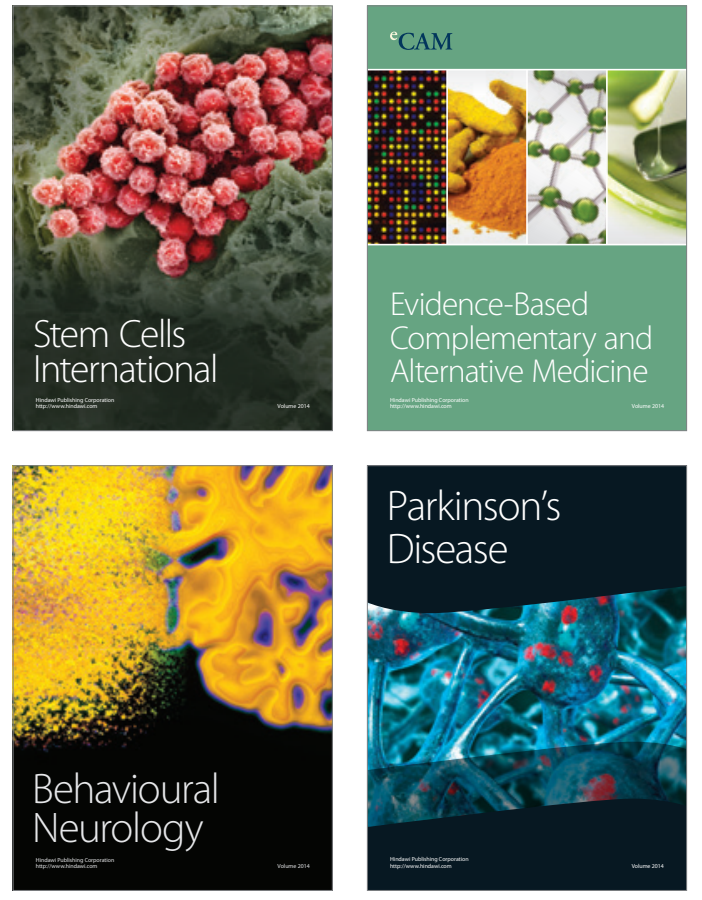
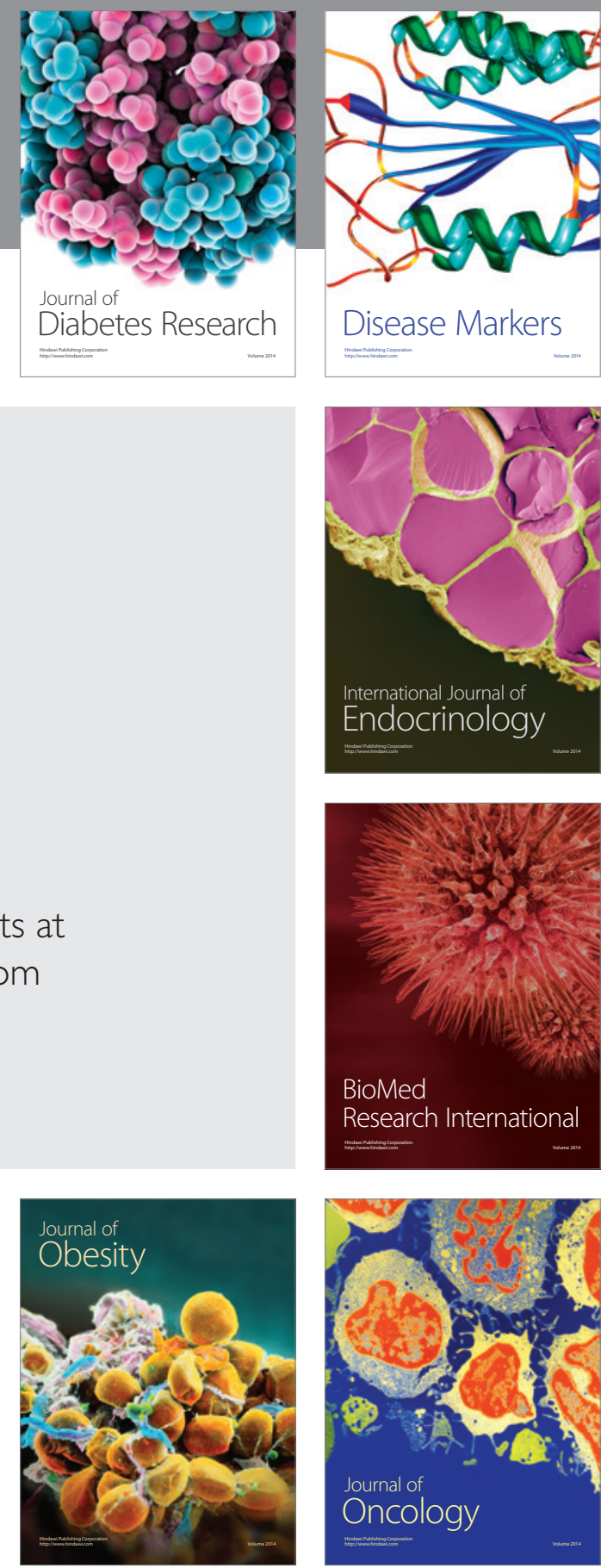

Disease Markers
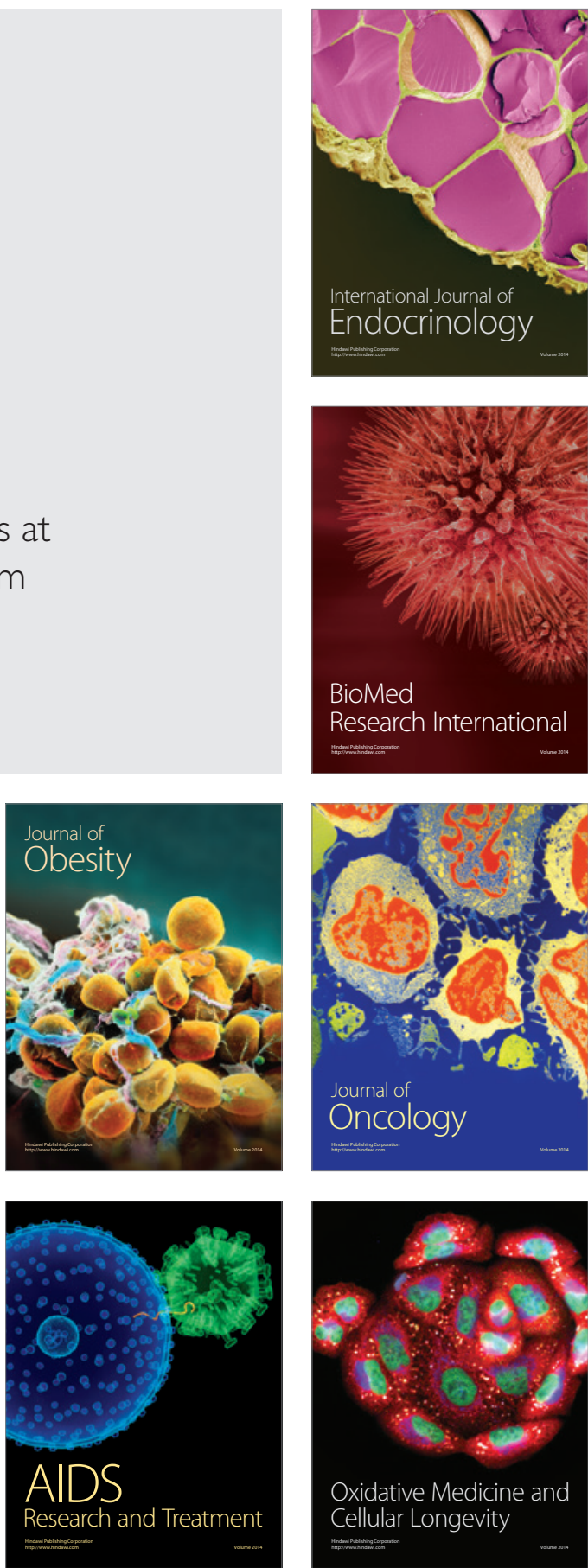